\title{
Oral salt supplements to compensate for jejunostomy losses: comparison of sodium chloride capsules, glucose electrolyte solution, and glucose polymer electrolyte solution
}

\author{
J M D Nightingale, J E Lennard-Jones, E R Walker, M J G Farthing
}

\begin{abstract}
Six patients with jejunostomies and residual jejunal lengths of 105 to $250 \mathrm{~cm}$ took the same food and water each day for eight study days. In random order, three methods of salt replacement were tested, each over 48 hours, against a period without added salt. During the three test periods the patients took $120 \mathrm{mmol}$ of sodium chloride daily, as salt in gelatine capsules, as an isotonic glucose electrolyte (280 mOsmol/ $\mathrm{kg} ; 30 \mathrm{kcal})$ solution, and as a glucose polymer (Maxijul) solution (280 $\mathrm{mOsmol} / \mathrm{kg} ; 200 \mathrm{kcal}$ ). The daily stomal output remained constant for each patient during the four test periods but varied between patients from 0.60 to $2.84 \mathrm{~kg}$ (daily intestinal fluid balance $0.74-2.61 \mathrm{~kg}$ ). Without a salt supplement, three patients lost more sodium from the stoma than they took in by mouth $(-25,-94$, and $-101 \mathrm{mmol} /$ day) and the mean sodium balance for all six subjects was $-16 \mathrm{mmol}$ (range -101 to 79 ) daily. Extra salt was absorbed with each form of supplement $(\mathbf{p}<0.05)$; no patient with the glucose electrolyte solution (mean 96, range 0 to $226 \mathrm{mmol}$ ), but one patient with the glucose-polymer solution (mean 96, range -25 to $164 \mathrm{mmol}$ ) and two with the salt capsules (mean 66 , range -8 to $145 \mathrm{mmol}$ ) were in negative balance. Two patients vomited with the salt capsules. There was only a small increase in energy absorption (mean $115 \mathrm{kcal}$ ) with the glucose polymer solution compared with the glucose electrolyte solution. A sipped glucose electrolyte solution seems to be the optimal mode of sodium replacement in patients with a high output jejunostomy.
\end{abstract}

Patients with an end jejunostomy often have high losses of fluid and electrolytes that can necessitate long term oral or parenteral supplements. ${ }^{12}$ These losses can be reduced by taking an oral glucose and electrolyte solution..$^{3-5}$ Animal and human jejunal perfusion experiments have suggested that the optimal concentration of sodium in the solution to maximise absorption is about $120 \mathrm{mmol} / \mathrm{l}^{6-9}$ Glucose enhances the absorption of sodium in the jejunum when its concentration is $14 \mathrm{mmol} / \mathrm{l}$ or more. Glucose is thus used to make a salt solution isotonic $(280 \mathrm{mOsmol} / \mathrm{kg}$ ). A glucose polymer may be advantageous ${ }^{10}$; it allows more glucose to be dissolved in an isotonic solution and so provides added energy. In this study we aimed to determine if sodium chloride capsules taken with food are as effective as a glucose electrolyte solution containing the same amount of sodium chloride. We also investigated whether a glucose polymer (Maxijul) replacing glucose in the electrolyte solution can increase the amount of sodium and/or energy absorbed.

\section{Method}

Six patients (Table I), who had undergone colectomy and small intestinal resection resulting in a stoma were studied. Each had less than $250 \mathrm{~cm}$ jejunum remaining. In two the jejunal length was determined at operation and in four from a barium follow through examination using an opisometer." All were studied more than two years after the last bowel resection and all were maintaining satisfactory nutritional, fluid, and electrolyte status. They ate food but one also received intravenous nutrition and another intravenous fluid and electrolyte supplements to maintain health.

\section{STUDY DESIGN}

On each study day each patient took a constant chosen diet eaten at the same times. Likewise, fluids were drunk in the same amounts and at the same times. The patients continued with their usual antidiarrhoeal and other medications. The total duration of the study was 11 days. Four different treatments were given in random order, each for two days and with a day's break between each study period. The intestinal effluent for study days was pooled to give 24 hour collections. The results are expressed as the mean of two days.

\section{REGIMENS TESTED}

(1) Glucose electrolyte solution: $7 \mathrm{~g} \mathrm{NaCl}(120$ mmol sodium $)+8 \mathrm{~g}$ glucose $(45 \mathrm{mmol})$ made up to a litre with tap water $(280 \mathrm{mOsmol} / \mathrm{kg} ; 30 \mathrm{kcal})$.

(2) Glucose-polymer electrolyte solution: $7 \mathrm{~g}$ $\mathrm{NaCl}(120 \mathrm{mmol}$ sodium $)+55 \mathrm{~g}$ glucose polymer (Maxijul, Scientific Hospital Supplies Ltd) made up to a litre with tap water $(280 \mathrm{mOsmol} / \mathrm{kg}, 200$ $\mathrm{kcal})$.

(3) Salt capsules: $14 \times 500 \mathrm{mg}$ salt capsules ( $8.55 \mathrm{mmol}$ each) 4 taken with breakfast, 5 with lunch, and 5 with supper (total $120 \mathrm{mmol}$ sodium) and a litre of tap water.

(4) Tap water: 1 litre of tap water and no salt supplements. 
LABORATORY MEASUREMENTS

A duplicate oral intake and the intestinal output were weighed, homogenised, and aliquots stored at $-20^{\circ} \mathrm{C}$. Total sodium and potassium were measured by flame photometry. Samples were freeze dried, weighed, and their energy content determined by bomb calorimetry. ${ }^{12}$

\section{Results (Table II)}

\section{PATIENT TOLERATION}

The salt capsules were tolerated well by four patients but caused vomiting on both days for patient $\mathrm{D}$ and on one day for patient $\mathrm{B}$. The two electrolyte solutions were considered palatable by all the patients.

\section{WEIGHT (Fig A)}

The difference between weight of food and fluid consumed and the jejunostomy output was positive (that is, there was net absorption) and

TABLE I Patient details

\begin{tabular}{llllll}
\hline Patient & Age/sex & Diagnosis & $\begin{array}{l}\text { fejunal } \\
\text { length }(\mathrm{cm})\end{array}$ & $\begin{array}{l}\text { Time from } \\
\text { resection(months) }\end{array}$ & $\begin{array}{l}\text { Antidiarrhoeal } \\
\text { therapy }\end{array}$ \\
\hline A & $40 \mathrm{~F}$ & CD & $100^{\star}$ & 185 & IVF \\
B & $26 \mathrm{~F}$ & CD & 105 & 24 & IVN, C, L \\
C & $65 \mathrm{~F}$ & CD & $110^{\star}$ & 72 & C, L \\
D & $57 F$ & UC & $120^{\star}$ & 36 & Nil \\
E & $56 \mathrm{M}$ & CD & 160 & 148 & L \\
F & $59 \mathrm{~F}$ & CD & $250^{\star}$ & 55 & Nil \\
\hline
\end{tabular}

$\star$ : $x$ ray assessment of bowel length.

IVN: intravenous nutrition, 31 daily.

IVF: intravenous electrolyte 11 daily.

C: codeine $60 \mathrm{mg}$ four times a day half an hour before food

L: loperamide $4 \mathrm{mg}$ four times a day half an hour before food. UC: ulcerative colitis.

CD: Crohn's disease.

TABLE II Weight, sodium, potassium, and energy content of the oral intake and intestinal output

\begin{tabular}{|c|c|c|c|c|c|}
\hline \multirow{2}{*}{\multicolumn{2}{|c|}{ Patient intake }} & \multicolumn{4}{|l|}{ Output } \\
\hline & & $\begin{array}{l}\text { No } \\
\text { supplement }\end{array}$ & $\begin{array}{l}\text { Salt } \\
\text { capsules }\end{array}$ & $\begin{array}{l}G E \\
\text { solution }\end{array}$ & $\begin{array}{l}\text { GP } \\
\text { solution }\end{array}$ \\
\hline \multicolumn{6}{|c|}{ Weight $(\mathrm{kg})$ : } \\
\hline A & 3.58 & $2 \cdot 67$ & $2 \cdot 81$ & $2 \cdot 84$ & $2 \cdot 74$ \\
\hline B & 3.67 & $2 \cdot 08$ & $2 \cdot 39$ 太 & $2 \cdot 1^{\star}$ & 1.97 \\
\hline C & $3 \cdot 21$ & 0.6 & 0.71 & 0.72 & 0.62 \\
\hline D & 3.68 & $1 \cdot 28$ & - & 1.08 & 1.47 \\
\hline $\mathrm{E}$ & 4.53 & $2 \cdot 28$ & $2 \cdot 27$ & $2 \cdot 81$ & $2 \cdot 18$ \\
\hline $\mathrm{F}$ & $4 \cdot 62$ & $2 \cdot 59$ & $2 \cdot 55$ & 255 & 2.58 \\
\hline \multicolumn{6}{|c|}{ Sodium (mmol): } \\
\hline A & 158 & 252 & 284 & 278 & 260 \\
\hline B & 148 & 173 & $200^{\star}$ & $163^{\star}$ & 157 \\
\hline C & 111 & 73 & 86 & 85 & 75 \\
\hline D & 230 & 151 & - & 124 & 186 \\
\hline $\mathrm{E}$ & 238 & 230 & 229 & 274 & 204 \\
\hline $\mathrm{F}$ & 200 & 301 & 328 & 305 & 345 \\
\hline \multicolumn{6}{|c|}{ Potassium (mmol): } \\
\hline A & 79 & 13 & 12 & 12 & 13 \\
\hline B & 64 & 14 & $31^{\star}$ & $20^{\star}$ & 14 \\
\hline $\bar{C}$ & 67 & 8 & 9 & 8 & 11 \\
\hline D & 71 & 12 & - & 9 & 10 \\
\hline E & 133 & 12 & 14 & 16 & 14 \\
\hline $\mathrm{F}$ & 78 & 14 & 10 & 7 & 10 \\
\hline \multicolumn{6}{|c|}{ Energy (kcal): } \\
\hline A & 2696 & 1124 & 1157 & 993 & 1152 \\
\hline B & 2296 & 945 & $1041^{\star}$ & $704^{\star}$ & 844 \\
\hline C & 1612 & 234 & 259 & 297 & 241 \\
\hline D & 1871 & 396 & - & 348 & 662 \\
\hline $\mathrm{E}$ & 3712 & 1570 & 1663 & 1614 & 1525 \\
\hline $\bar{F}$ & 2018 & 398 & 398 & 516 & 496 \\
\hline
\end{tabular}

GE: glucose-electrolyte solution.

GP: glucose-polymer solution.

$\star$ : only one day measured.

-: patient vomited both days.

The oral intake results shown are for the day with no supplements only. $120 \mathrm{mmol}$ more sodium was consumed on the sodium supplement days, $30 \mathrm{kcal}$ on the glucose electrolyte days and $200 \mathrm{kcal}$ on the glucose polymer days. constant for each patient throughout the study $(0.74$ to $2.61 \mathrm{~kg})$.

\section{SODIUM (Fig B)}

The sodium concentration in the stomal output varied from 78-134 mmol/l (mean 106). Without a sodium supplement there was a net loss of sodium in three patients $(-25,-94$, and -101 $\mathrm{mmol} /$ day). Two of these three were maintained on long term parenteral supplements mainly because of recurrent episodes of dehydration. For all six patients the mean sodium balance was $-16 \mathrm{mmol} /$ day (range -101 to 79 ). Sodium supplements improved the sodium balance in all patients $(\mathrm{p}<0.05$ using the Wilcoxon signed rank test for two related samples). No patient was in negative sodium balance with the glucose electrolyte solution (mean 96, range 0-226 $\mathrm{mmol} /$ day). One patient was in negative balance with the glucose polymer electrolyte solution (mean 96, range -25 to $164 \mathrm{mmol} /$ day), and two of five patients with salt capsules (mean 66, range -8 to $145 \mathrm{mmol} /$ day).

\section{POTASSIUM}

The mean stomal potassium concentration was $7 \cdot 5 \mathrm{mmol} / \mathrm{l}$ (range $2 \cdot 7-18$ ), The mean potassium balance was positive ( $70 \mathrm{mmol}$, range $33-121)$ in all patients throughout the study and changed little with salt supplements.

ENERGY (Fig C)

The mean energy absorbed with the glucose
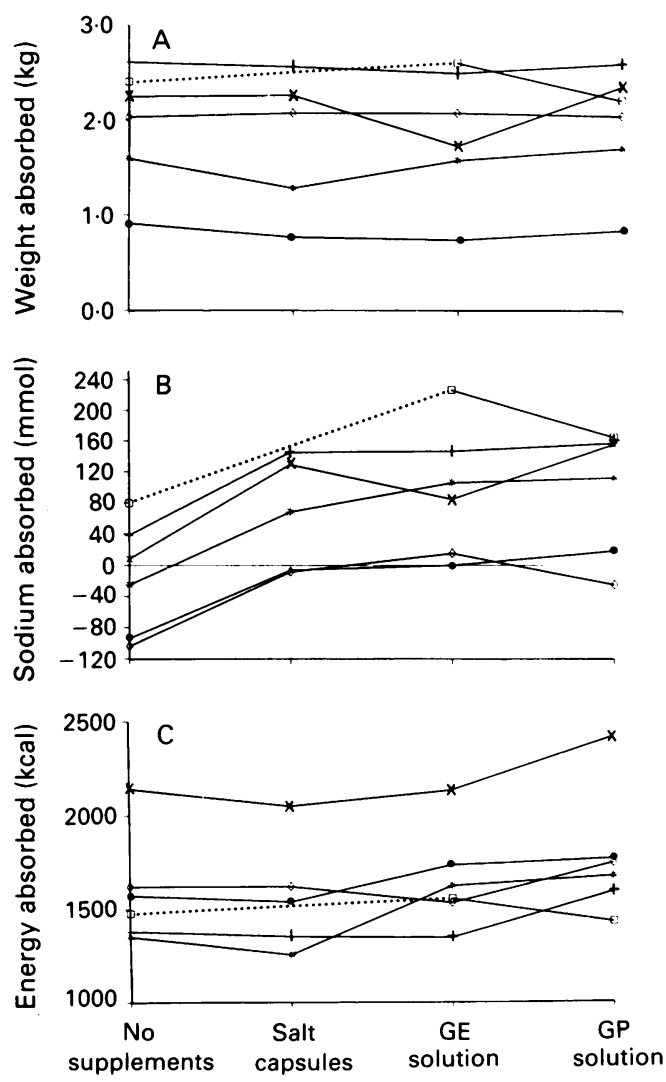

Net (oral intake - stomal output) of fluid $(A), \operatorname{sodium}(B)$, and energy $(C)$ for no supplements, salt capsules, glucose electrolyte solutions $(G E)$ and glucose polymer solution $(G P)$ for each of the six patients. $\left(\cdot A,{ }^{\star} B,+C, \square D, \times E, \diamond F\right)$ 
polymer electrolyte solution was $1512 \mathrm{kcal} /$ day (range 871-1764), compared with a mean of 1396 $\mathrm{kcal} /$ day (range 592-1733) with the glucose electrolyte solution.

\section{Discussion}

Three of the six patients in this study were in negative sodium balance without an oral salt supplement, and two of these were receiving long term parenteral supplements because of recurrent episodes of sodium deficiency. All of these patients achieved a positive sodium balance with a sodium supplement of $120 \mathrm{mmol}$ daily. The mode of sodium administration was not critical, though there was a marginal advantage for the electrolyte solutions as the salt capsules caused vomiting in two patients. The substitution of a glucose polymer for glucose in the electrolyte solution did not result in more sodium absorption and gave a small $(116 \mathrm{kcal})$ but not clinically important increase in the energy absorbed.

Previous work has shown that drinking water or sodium solutions with a concentration of less than $90 \mathrm{mmol} / \mathrm{l}$ leads to a negative sodium balance in patients with a high jejunostomy. ${ }^{89}$ This is because the jejunum cannot absorb sodium against a steep electrochemical gradient and depends for its absorption on glucose or amino acid coupling and water movement. If the sodium concentration in the lumen of the jejunum is less than $90 \mathrm{mmol} / \mathrm{l}$, sodium tends to move into the lumen and so is lost from the body via the stoma.

Most rehydration solutions given to patients with jejunostomies ${ }^{45}$ have been based on the World Health Organisation solution which contains $90 \mathrm{mmol} / \mathrm{l}$ sodium. ${ }^{13}$ We used a higher concentration of $120 \mathrm{mmol} / \mathrm{l}$ as perfusion studies $^{4-8}$ and work done in our laboratory ${ }^{9}$ had suggested this higher concentration may lead to more sodium absorption.
This experiment was designed to test whether a glucose or glucose polymer electrolyte solution has an advantage over taking sodium chloride as capsules with food. The advantage was found to be slight and related more to palatability than to efficiency of absorption. Patients with a high jejunostomy can thus be offered a sodium supplement either as capsules or as a glucose electrolyte solution with a sodium concentration of $120 \mathrm{mmol} / \mathrm{l}$. The latter can be made up simply using tap water and measuring scoops.

1 Nightingale JMD, Lennard-Jones JE, Walker ER, Farthing MJG. Jejunal efflux in short bowel syndrome. Lancet 1990 336: 765-8.

2 Nightingale JMD, Lennard-Jones JE, Gertner DJ, Wood SR, Bartram CI. Colonic preservation reduces the need for parenteral therapy, increases the incidence of renal stones, parenteral therapy, increases the incidence of renal stones,
but does not change the high prevalence of gall stones in but does not change the high prevalence of gall st
patients with a short bowel. Gut 1992; 33: (in press).

3 Griffin GE, Fagan EF, Hodgson HJ, Chadwick VS. Enteral therapy in the management of massive gut resection complitherapy in the management of massive gut resection compli-
cated by chronic fluid and electrolyte depletion. Dig Dis $S_{c i}$

4 Newton CR, Gonvers JJ, McIntyre PB, Preston DM, Lennard-Jones JE. Effect of different drinks on fluid and electrolyte losses from a jejunostomy. $\mathcal{F} R$ Soc Med 1985; 78: $27-34$.

5 MacMahon RA. The use of the world health organization's oral rehydration solution in patients on home parenteral nutrition. $\mathcal{F} P E N$ 1984; 8: 720-1.

6 Sladen GE, Dawson AM. Interrelationships between the absorptions of glucose, sodium and water by the normal human jejunum. Clin $S_{c i}$ 1969; 36: 119-32.

7 Fortran JS. Stimulation of active and passive sodium absorption by sugars in the human jejunum. $f$ Clin Invest $1975 ; 55$ : 728-37.

8 Spiller RC, Jones BJM, Silk DBA. Jejunal water and electrolyte absorption from two proprietary enteral feeds in man importance of sodium content. Gut 1987; 28: 681-7.

9 Rodrigues CA, Lennard-Jones JE, Thompson DJ, Farthing MJG. What is the ideal sodium concentration of oral rehydration solutions for short bowel patients? Clin $S_{C l}$ 1988; 74 (suppl 18): 69P.

10 Saunders DR, Sillery JK. Absorption of carbohydrateelectrolyte solutions in rat duodenojejunum. Implications for the composition of oral electrolyte solutions in man for the composition of oral
Dig Dis Sci 1985; 30: $154-60$

11 Nightingale JMD, Bartram CI, Lennard-Jones JE. Length of residual small bowel after partial resection: Correlation between radiographic and surgical mesurements. Gastrointest Radiol 1991; 16: 305-6.

12 Miller DS, Payne PR. A ballistic bomb calorimeter. Br 7 Nutr 1959; 13: 501-8.

13 Avery ME, Snyder JD. Oral therapy for acute diarrhoea. The underused simple solution. $N$ Englf $\mathrm{Med}$ 1990; 323: 891-t. 